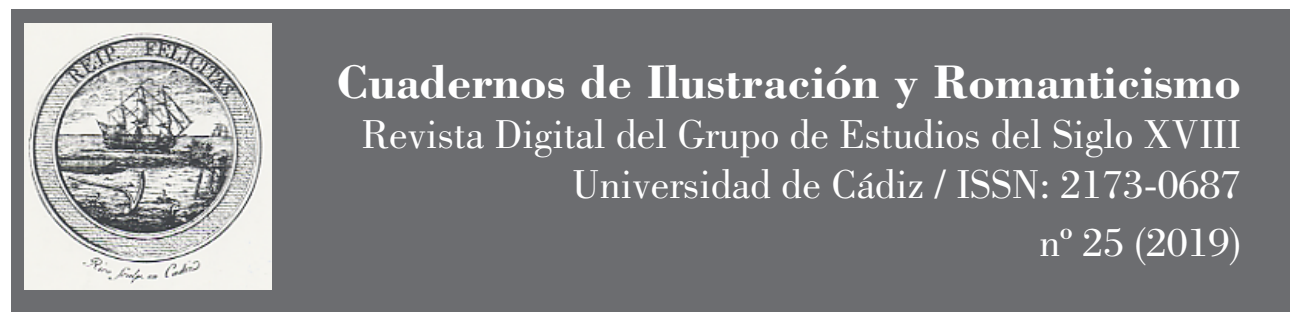

\title{
JUAN NICASIO GALLEGO EN EL IMAGINARIO NACIONAL
}

\author{
Eduardo Fernández LóPEZ \\ (Grupo de Estudios Históricos «Esteban Boutelou»)
}

Recibido: 10-02-2019 / Revisado: 10-06-2019

Aceptado: 10-06-2019 / Publicado: 20-12-2019

Resumen: Juan Nicasio Gallego fue un sacerdote, poeta y político que desplegó una intensa actividad durante la primera mitad del siglo XIX. Entró a formar parte de los círculos culturales y literarios de la Corte desde los primeros años de su vida, algo que a la larga le granjearía grandes amistades que velaron por su vida cuando el poder le dio la espalda. Diputado suplente por Zamora en las Cortes de Cádiz de 1812, se convirtió en uno de los diputados más importantes, y que más discutió y luchó para que la primera constitución española saliera adelante. Caería en desgracia, sería perseguido y encarcelado por el absolutismo a la vuelta de Fernando VII en 1814, y volvería al exilio en Francia durante unos meses tras la segunda restauración fernandina. Mientras tanto dedicaría su vida a la creación poética y a servir de ayuda a jóvenes escritores que encontraron en él un protector y un amigo. Conseguiría el perdón real y recuperar sus privilegios dentro de la Corte en la parte final de su vida, y en ese momento sería reconocido como gran poeta y encumbrado como Secretario Perpetuo de la Real Academia Española entre otros puestos. Palabras Clave: Historia contemporánea, Constitución, Guerra de la Independencia, Fernando VII, Poesía anacreóntica, Romanticismo, Historia cultural y literaria del siglo XIX.

\section{JUAN NICASIO GALLEGO IN THE NATIONAL IMAGINARY}

AвSTRACT: Juan Nicasio Gallego was a priest, poet and politician who displayed an intense activity during the first half of the 19th century. He became part of the cultural and literary circles of the Court from the first years of his life, something that in the long run would earn him great friendships who watched over his life when power turned his back on him. Deputy substitute for Zamora in the Cortes de Cádiz of 1812, he became one of the most important deputies, and he argued more and fought for the first Spanish constitution to go ahead. He would fall to misfortune, be persecuted and imprisoned by absolutism after Ferdinand VII in 1814, and return to exile in France for a few months after the second Fernandina restoration. Meanwhile he would dedicate his life to the poetic creation and to help young writers who found in him a protector and a friend. $\mathrm{He}$ would obtain real pardon and recover his privileges within the Court in the final part of his life, and at that moment he would be recognized as a great poet and a lofty Perpetual Secretary of the Royal Spanish Academy among other posts.

KeYwords: Contemporary History, Constitution, War of Independence, Ferdinand VII, Anacreontic Poetry, Romanticism, Cultural and Literary History of the 19th Century. 


\section{i. Aproximación biográfica}

El inicio del siglo XIX en España coincide con una serie de hechos de gran importancia histórica y política para el país. Alteraciones que representan el cambio de mentalidad en una importante parte de los habitantes no solo de un país, sino de un Imperio, así como el abandono definitivo del Antiguo Régimen. Mientras la España peninsular se enfrentaba a la invasión de las tropas francesas de Napoleón Bonaparte, dividida entre afrancesados; que veían en la Ilustración francesa la solución a tantos años de oscurantismo, y patriotas; defensores de los principios básicos de la tradición española, a la sazón la monarquía absolutista y el clero más reaccionario. Por su parte, los territorios españoles de América comenzarán a despertar y a levantarse, primero mediante la creación de Juntas similares a las aparecidas en España durante la invasión francesa, y más tarde con las armas, en busca de un autogobierno primero, y de una total independencia más tarde.

En este estado bélico y constitucionalista es donde aparecerá Juan Nicasio Gallego; un diputado de las Cortes de Cádiz que si bien en un primer momento ocuparía una plaza de suplente debido al caos reinante en el interior del país, y a la falta de comunicaciones entre unos y otros lugares, acabaría convirtiéndose en uno de los representantes más fecundos en participaciones y propuestas dentro de la cámara gaditana, además de ser uno de los prohombres más importantes que la provincia de Zamora ha dado a la historiografía española.

Sin embargo, hablar de Juan Nicasio Gallego es mucho más que hacer referencia a las Cortes de Cádiz y a su Constitución. Hablar del sacerdote y poeta zamorano es hacerlo de varias épocas decisivas y capitales para el devenir de España, de los reinados de Carlos IV, Fernando VII e Isabel II, de la guerra de la Independencia y de la Constitución de Cádiz, de liberalismo, de la persecución absolutista, de poesía y de teatro, de Romanticismo - o anti romanticismo-, de la Universidad de Salamanca, de Juan Meléndez Valdés, de los duques de Frías, de la Real Academia Española y de los mayores nombramientos eclesiásticos y políticos que podían darse en aquella España de mediados del siglo xix; tales como el de senador vitalicio del Reino, o el de miembro supernumerario del Tribunal de la Rota de la Nunciatura.

Será por la importancia de su figura que su persona se reflejará de manera amplia en diferentes obras y medios periodísticos, donde se expondrán las numerosas cualidades y características del sacerdote, político y poeta zamorano, aunque si bien es cierto tendremos que esperar a que Nicasio Gallego consiga el perdón real tras haber participado en las Cortes gaditanas, y haber seguido la corriente liberal, para que ya con una segunda vuelta a la Corte madrileña sea reconocido no solo por sus amigos y seguidores, sino por la sociedad madrileña en general; siendo en ese momento cuando más recursos y más apariciones suyas encontremos en el imaginario nacional.

\section{Juan Nicasio Gallego en el imaginario nacional}

Aparecerá su nombre junto a una mínima descripción por primera vez en los prolegómenos del arco de años en los que centraremos nuestro periodo de estudio, pero no me resisto a apuntarlo; pues es una referencia tan necesaria como fugaz. Será dentro del registro de exámenes de estudiantes, documento necesario para ingresar en la Facultad Mayor de la Universidad de Salamanca donde Nicasio Gallego llevará a cabo sus estudios de derecho, cuando en el año de I79r aparecerá el zamorano en una lista de recién matriculados de la siguiente manera: «Don Juan Nicasio Gallego, nacido en la ciudad 
de Zamora. I4 años. Pelo y ojos castaños». (Archivo histórico de la Universidad de Salamanca, Registro de exámenes, vol. 7, I769-1817: 246).

Esta limitada descripción del personaje sería la única que tendríamos de él hasta que, muchos años después, Leopoldo Augusto de Cueto en el año I875, dentro de su Biblioteca de autores españoles, volviera a describirlo para la posteridad. Esta descripción, hecha del sacerdote político y poeta zamorano, asegura que era de aventajada estatura, corpulento, de tez morena e irónico, campechano, de buen carácter, de expresión moderada pero firme, gustoso de tertulias y asmático. Una descripción mucho más pormenorizada del zamorano, a la que podríamos añadir un par de detalles: la primera sobre el tono de su voz, a la que su buen amigo el marqués de Molíns llegaría a calificar de «estertórea», (Freire, 223: 294) y una más sobre tamaño y altura, si nos fijamos en el apelativo que usa Mor de Fuentes para referirse a él en su obra Bosquejillo de la vida y escritos, donde lo denomina «Nicasio Galleguísimo». (Mor de Fuentes, 1836: 217).

Aunque sin duda el que mejor ahonda en la importante, y llamativa, envergadura del zamorano, será Benito Pérez Galdós en uno de sus Episodios Nacionales, Los Apostólicos del año 1879, donde el padre Alelí narra a sus compañeros de mesa como fue el encuentro con Juan Nicasio Gallego en el centro de Madrid:

Iba yo por la calle de Carretas arriba, y al llegar a la esquina de Majaderitos veo que viene hacia mí un monstruo con sotana y manteo; pero yo que conozco a mis fieras me dejé abrazar y le abracé también con mucho gozo. « ¿ómo va? Bien, ¿y tú, gigantón?»... En fin, para no cansar, era Juan Nicasio Gallego. (Pérez Galdós, 2008: 76).

Una aparición ésta, en la obra del escritor canario, a la que volveremos de nuevo más adelante, pues en ella además de dicha descripción, dará cuenta el personaje, representado por Alelí, de algunos de los episodios más rocambolescos de la biografía del zamorano.

Otros, irán más allá en la imagen que proyecten, en sus obras y escritos, sobre la imagen de Juan Nicasio Gallego. Ferrer del Río, por ejemplo, se refiere a su figura como literato de la siguiente manera:

Gallego esgrime las armas del ridículo con singular destreza: anatomiza lo que es objeto de su censura periodo á periodo, frase á frase, vocablo á vocablo y lo destruye: su crítica zumbona es más amena que instructiva: nunca traspasa los límites del decoro, juega felizmente con el idioma, no moja su pluma en veneno, y sin embargo las heridas que produce son mortales. (Ferrer del Río, i846: 43).

A pesar de ello, su figura sería un referente más que conocido y venerado, pues según aseguraba Ventura de la Vega en una semblanza escrita en el año I842, y recogida en la publicación Museo de las familias, no había en España ninguna persona que amara, o fuera aficionado, a las bellas letras que no pronunciara con respeto el nombre del zamorano:

No hay poeta ni escritor público de cualquier género que sea, desde los más humildes hasta los más empinados de nuestra época, que no le consulte sus obras y haga de ellas sin más examen, cuantas correcciones le indique: no hay discusión literaria que no se termine a su arbitrio: no hay en fin quien ose replicar al que en materias de buen gusto ausenta una opinión, aludiendo: así piensa don Juan Nicasio Gallego. (Museo de las Familias, año I, nº I, 25-I-I842: 65). 
Sin embargo, o más bien a pesar de todos los posteriores reconocimientos, no lo tendría fácil Juan Nicasio Gallego para hacerse respetar en su vuelta a Madrid, y eso después de, incluso, contar con el apoyo de Fernando VII; que había pasado de perseguirlo a tenerlo, o intentarlo al menos, protegido entre algodones. Será en este momento, con la aparición en escena de la figura de Francisco Tadeo Calomarde, a la sazón ministro de Gracia y Justicia, cuando ocurriría uno de los acontecimientos más extraños que sufriría Juan Nicasio Gallego en su dilatada vida.

Este hecho aparecerá reflejado en la charla que el padre Alelí mantiene con el resto de los comensales que Pérez Galdós representa en Los Apostólicos. Durante la charla, y una vez que Alelí había narrado su encuentro con el zamorano, el resto de los comensales le recriminarán sus divagaciones a la hora de narrarles el encuentro con el zamorano y el caso del democracio que se había colado en su celda, a lo que el eclesiástico contestará de la siguiente manera:

Gallego es también un grande y descomedido democracio, y a eso iba... Pues me contó Juan Nicasio como le está engañando Calomarde, fingiéndole protección, y cómo el Rey le ha prometido no sé cuántas prebendas sin darle ninguna. Además, el hombre está temblando porque le han delatado por frac-masón, y bien sabemos todos que el año 8 fue empleado de los liberales en Cádiz, y el año ro diputado en las pestíferas Cortes. (Pérez Galdós, 2008: 76-77).

Este hecho narrado por el eclesiástico a su público hace referencia a un hecho real, ocurrido en la capital después de que el monarca reparara a Nicasio Gallego de todas las vejaciones que él mismo le había infringido, y que ahora el ministro de Gracia y Justicia, ferviente perseguidor de liberales, continuaba llevando a cabo a escondidas de Fernando VII. En mayo de r83o, después de que el monarca invitara a la Corte, y a su despacho, al zamorano para aclarar lo ocurrido; «recibiría éste de boca de Calomarde, situado en un lugar indefenso ante el rey, todas las promesas posibles, y en el tono más amistoso y cordial que estuvo en su mano». (Pastor Díez, 1845: 39).

Nada más lejos de realidad pues, una vez que hubo terminado el paripé cortesano, Calomarde comenzaría a poner en funcionamiento su plan para hundir de nuevo al zamorano. Llamaría el ministro al subdelegado principal de policía de la ciudad de Madrid, para convenir con él la idea de fraguar contra Juan Nicasio Gallego un expediente en el que el zamorano quedara como un hombre revolucionario y peligroso. Sin embargo, y a pesar de tener claro el dossier acusatorio que iban a montar contra el zamorano, el ministro de Gracia y Justicia decidió también que deberían seguirlo, por si encontraban en su comportamiento algo real que pudiera ponerle entre la espada y la pared.

El subdelegado de la policía de la Corte, encomendará esta labor en uno de sus satélites asalariados, quién a la postre demostraría su incapacidad como espía, pues en vez de seguir al bibliotecario del duque de Frías, lo haría con el archivero, e incluso llegaría a expresar en uno de sus informes que el vigilado «había llevado esa misma mañana de la mano a la escuela a un niño que le llamaba padre». (Pastor Díaz, 1845: 42).

A pesar del flagrante error de su esbirro, el subdelegado principal de policía le enviaría al ministro Calomarde un falso documento redactado por él mismo para que éste le diera el visto bueno antes de hacérselo llegar a Fernando VII. En esta nota falsa, y que nos ha llegado gracias a que Pastor Díaz, amigo íntimo del zamorano, la publicará en su Galería de Españoles celebres de I845, podemos leer una serie de calumnias que a cualquiera persona, conocedora de las andanzas del zamorano le sonará, como mínimo, rocambolesca. En ella, bajo la advertencia de «Muy importante» se podía leer lo siguiente: 
Tengo entendido que se halla en esta Corte el famoso democracio don Nicasio Gallego, diputado á Cortes por Zamora en el año I3 y posteriormente en los años 2I, etc. A este señor sacerdote le llamaban el padre de la Constitución porque fue uno de los individuos que la compusieron, posterior al años I4 le desterró S.M. á la Cartuja del Paular; y habiendo sido uno de los diputados proscriptos por el rey N.S.: es íntimo relacionado con Beltrán de Lis; y su hijo don Luís parece venia á reunirse á éste por hallarse de acuerdo para llevar á efecto la revolución y sublevar sus partidarios: también parece ser que están en comunicación con el vizconde de las Huertas para el dicho efecto; por lo que tengo medio averiguado que los dichos pertenecen al movimiento revolucionario que tenían tramado en la Habana (y que oportunamente se ha descubierto), el cual parece ser se extendía hasta nuestra corte. Todo esto lo hace creíble la multitud de acontecimientos políticos que se tocan, y precisamente en el mismo tiempo en que don Luis Beltrán de Lis vino de Francia, don Juan Nicasio Gallego de Inglaterra y el vizconde de las Huertas de la Coruña. También se halla en esta Corte el famoso rey de Valladolid, y el terrible Alcalá, comerciante de Salamanca: estos dos últimos se reúnen mucho con otros, y sus conferencias las tienen en el Observatorio del Buen Retiro. Lo que pongo en conocimiento de V.S. para los efectos convenientes. Madrid $\mathrm{r}^{\mathrm{o}}$ de junio de I830. Sr. subdelegado principal de policía. (Pastor Díaz, 1845: 40).

La conclusión de este episodio tan singular como peligroso para Juan Nicasio Gallego, lo recrearía Pérez Galdós en la continuación de la conversación dirigida por el padre Alelí de la siguiente manera:

Pues dijo que está empleado en la biblioteca del duque de Frías y que hace poco le fueron a prender por revoltoso, y equivocándose los de la policía, en vez de cogerle a él cogieron al archivero y le plantaron en la cárcel. Cuando el Rey lo supo se rió mucho, y dijo a Calomarde: «Tan malos sois como tontos». Después, Gallego fue a ver al Rey, y como este tiene debilidad por los poetas... (Pérez Galdós, 2008: 77).

Sería de ese modo, como se libraría Juan Nicasio Gallego de la malquerencia de Calomarde. En la obra, Galdós, denominará en boca del padre Alelí a Juan Nicasio Gallego como:

Padre de la Constitución, asegurando que así denominaba a Gallego la gente apostólica, y de esta manera también le calificó en su infame delación el religioso agonizante fray José María Díaz y Jiménez, ${ }^{\top}$ a quien nuestro soberano llama el número uno de los podencos por lo bien que huele, rastrea, señala y acusa toda conspiración y astucia de esos tontainas liberales. (Pérez Galdós, 2008: 78).

Pero si en algo destacó Juan Nicasio Gallego, más allá de su participación como diputado en las Cortes gaditanas de I8I2, fue en su labor como poeta. Serían fértiles los primeros años de Juan Nicasio Gallego como autor, sobre todo tras su llegada a Madrid para ser nombrado Director Eclesiástico del Real Colegio de Caballeros Pajes por el rey Carlos IV en I805, donde comenzó a publicar sonetos en el Memorial Literario. Sin

I Sería uno de los que antes enviaría a Calomarde los falsos informes, que éste demando a sus conocidos para formar una causa falsa contra Nicasio Gallego, cargados de calumnias y falsas acusaciones que hicieron feliz al ministro de Gracia y Justicia. 
embargo, y a pesar de llevar a cabo en esa época sus principales composiciones, ya comenzaba a mostrar el zamorano más interés por la obra de sus coetáneos que por la suya propia. A pesar de todo, sería en su segunda etapa en la Corte, la que comenzará en el año I830 y terminará con su fallecimiento en enero de 1853, cuando comenzaría a ser reconocido y valorado tanto por su obra como por su conocimiento de las letras.

Este conocimiento, y su buena formación clásica, le convertirían en una autoridad en materia literaria, y en un punto de referencia y consulta necesaria, le haría a la vez de lastre, impidiéndole comprender plenamente la revolución romántica que le sorprendería de lleno en la madurez personal y creativa. Era entonces el romanticismo la nueva forma de concebir la existencia de la realidad, pues se manifestaría no solo en la literatura, sino que lo haría también en el arte o la música. Era pues, «un movimiento que contaba desde su raíz con el ambiente de libertad que otros manifestaban desde años antes en el terreno político». (Freire, 2003: 297).

Durante este periodo, Juan Nicasio Gallego colaboraría en varias ocasiones con $\mathrm{El}$ Artista, ${ }^{2}$ a pesar de que la consideraba un elemento del Romanticismo recién instalado en el país. Esta publicación contaba con una doble función artística y política, pues servía de vía de escape para los ideales de los románticos, siendo, ante todo, un periódico en el que se manifiesta el descontento de todos por el escaso nivel cultural de España. En esta publicación se acuñaría el término clasiquista, que de forma peyorativa, venía a significar en lenguaje vulgar: rutinero, hombre para quien todo está dicho, o por mejor decir, lo estaba desde los tiempos de Aristóteles. Por supuesto, esta descripción se ajustaba de manera inigualable a la figura del poeta Nicasio Gallego.

Juan Nicasio Gallego que si tuvo algo de prerromántico, sin embargo siempre rechazo el Romanticismo, de hecho no utilizaría en ningún momento de su vida el apelativo de Romanticismo, ni Romántico. Definiendo el nuevo movimiento, las pocas veces que se refería a él, con la acepción de la nueva literatura o de la literatura actual, y siempre para asegurar que le desagradaba porque la consideraba una poesía «extravagante y con rarezas propias de un delirante», 3 y que «encontraba en ella una falta de autenticidad y de calidad literaria».4

A pesar de todos estos ataques y desplantes, Eugenio de Ochoa, con intención amistosa y conciliadora, insertará en El Artista una semblanza de Juan Nicasio Gallego en la que se señalará lo que de romántico tiene este poeta que se cree clásico. Entre otros ejemplos, se afirma en el artículo que en la elegía El Dos de Mayo,Juan Nicasio Gallego se desvía de su clasicismo anterior, y «no es fácil encontrar su tipo en la poesía clásica latina ni española», y que la elegía $A$ la muerte del duque de Fernandina «huele a romántica desde el primer verso hasta el último». (El Artista, año I, $\mathrm{n}^{\circ}$ I, 5-I-I835: 192-I96). Pues asegura Eugenio de Ochoa que:

Hay en ellos desiertos, bóvedas góticas, ecos de campanas, luz de luna, dolor profundo y severo, trozos dramáticos, irregularidad de estrofas, de cortes y de rimas, algo de aquel desorden semi-frenético en los sentimientos, en la frase y en las imágenes,

2 Periódico dominical de doce páginas. Fue un excelente ejemplo de revista artística en un momento de gran agitación política. El Artista, fue fundado por el escritor Eugenio Ochoa y por el pintor Federico Madrazo en I835. Sin duda fue un proyecto de juventud en la misma línea de la publicación francesa L'Artiste, de Achille Ricourt, al que, en ocasiones, llega a plagiar. Este semanario recoge la estética del Romanticismo que llega a España en esos momentos. De edición muy cuidada, casi lujosa, con litografía de gran calidad, estaba impreso por Sancha. El periódico sufriría graves problemas económicos y se publicaría solamente durante 15 meses.

3 Carta al marqués de Valmar enviada por Juan Nicasio Gallego en el año I835, publicada en Biblioteca de autores españoles, t. LXI, p. 226.

4 Ibidem. 
tan peculiar de la escuela moderna, muchas en fin de las dotes y adornos obligados de la poesía que posteriormente se conoce con el nombre de romántica», para concluir que Juan Nicasio Gallego «sin quererlo, y acaso sin advertirlo, sigue no muy de lejos la corriente del romanticismo, que reprueba y mira como una lastimosa corrupción del buen gusto. (El Artista, año I, ${ }^{\circ}{ }^{\circ}, 5^{-1-1835: ~ 192-I 96) . ~}$

En ese mismo número, El Artista identificará a Juan Nicasio Gallego con el prototipo del clasiquista a ultranza, como ya hemos indicado; «que lo definían como hombre para quien toda idea nueva es un sacrilegio; que no cree en los adelantos de las artes ni en los progresos de la inteligencia, porque es incapaz de concebirlos». (El Artista, año I, $\mathrm{n}^{\circ} \mathrm{I}$, 5-I-I835:36).

\section{El protector nato}

Más allá de ser un referente literario entre sus contemporáneos, imprimiría el zamorano su conocimiento y carisma sobre los jóvenes poetas, que veían en él una robusta estela a la que asirse en mor de conseguir el reconocimiento como futuros poetas.

En efecto, el señor Gallego fue en vida tan apreciado o más, por su gusto exquisito en la literatura y su bondadosa facilidad en dar seguidos consejos a cuantos acudían a consultar con él alguna producción, que por el número e importancia de las suyas propias. El señor Gallego es, sin duda, un acabado modelo en el arte de bien decir; su entonación poética rara vez deja algo que desear, pero lo amigos de las letras no pueden menos de lamentar vivamente que su fecundidad, o acaso sus aplicación para los trabajos literarios, en que tanta gloria hubiera podido ganar, fuesen en todo tiempo tan inferiores a lo que de su privilegiado talento y vasta instrucciones debía esperarse. (De Cueto López, 1875: 396).

Tal fue su dedicación hacia la obra de los demás, descuidando la suya de manera tan llamativa que, ya sea de forma consciente o inconsciente, no publicaría ningún libro en vida. Un detalle que no pasa desapercibido en la imagen que muchos de sus coetáneos ofrecen de él en sus escritos, como perfectamente puede apreciarse en las palabras, de nuevo, de Ferrer del Río sobre el zamorano en su Galería de la literatura española de i846:

Oye con paciente amabilidad á cuantos le consultan; no rehúsa consejos á quien se los pide; y rara vez derrama con sus amonestaciones la semilla del desaliento en el corazón de quien las solicita. A falta de escribir libros propios, pasa muchas horas en enmendar libros ajenos, porque es modelo de corrección y su voto inapelable en materia de buen gusto. (Ferrer del Río, 184: 43).

Debido a esta entrega, sus coetáneos comenzaron a conocerlo, y denominarlo, entre sus círculos más íntimos, como el Protector nato. Punto éste, en el que insistiría Augusto de Cueto.

El señor Gallego —escribía en I845 uno de sus biógrafos— es el protector nato, el amigo de confianza de todos los jóvenes que aspiran al glorioso timbre de poetas: él los aconseja, los anima, les corrige sus obras, y a todas horas están abiertas su puerta y su benevolencia para cuantos de buena fe van a reclamar el auxilio de sus luces y larga práctica en el arte. (De Cueto López, I875: 396). 
Esta entrega, la demostraría Juan Nicasio Gallego con muchos de los aspirantes a escritores que le rodearon durante la última etapa de su vida, pero este apoyo desinteresado quedaría de alguna manera reflejado de forma inequívoca en su relación con la escritora Gertrudis Gómez de Avellaneda.

Avellaneda llegaría a Madrid en el año I84I con una carta en la que Alberto Lista le recomienda a Juan Nicasio Gallego. Ese mismo año, Juan Nicasio Gallego prologaría su obra titulada Poesias, comentando con buen humor que en algunas de aquellas composiciones «se notaban ciertos suspiros de desaliento, desengaño y saciedad de la vida, que harán creer al lector, como nosotros creíamos al ver algunas muestras en un periódico de Cádiz, que son fruto de la edad madura, de esperanzas frustradas y de ilusiones desvanecidas por una larga y costosa experiencia». (Freire, 2000: 84). De ahí el asombro del poeta zamorano al conocer a la autora, llena de vida y de atractivo a sus veinticinco años. Tras esa sorpresa inicial, y encantado con Gertrudis de Avellaneda, escribirá Juan Nicasio Gallego:

Tal es la manía de la época: jóvenes robustos y de pocos años se lamentan del ningún aliciente que les ofrece este valle de lágrimas. Para ellos ya es una carga insoportable; la beldad no les inspira sino desvío, repugnancia o raptos frenéticos de pasión cuyo término es el ataúd. Para ellos el estudio no tiene halago, el campo amenidad, el cielo alegría, la sociedad placeres. El mundo no puede comprenderlos: todo en él les es violento, extraño, como a peces afuera del agua, o como a individuos de otro planeta caídos de pronto en este suelo mortífero y peregrino. (Freire, 2000: 84).

Su gran amistad con Gertrudis Gómez de Avellaneda, haría que las obras de la escritora fuesen habitualmente corregidas por el propio Juan Nicasio Gallego; quien defendía a la autora si era necesario, aseguraban algunos, violentamente. Esta férrea defensa de su apadrinada debió de ser real, pues asíllegó a recogerlo entre sus páginas El Dómine Lucas, ${ }^{5}$ periódico satírico de aquella época, donde se aseguró que en cierta ocasión que en un estreno poco afortunado de una de las obras de Gertrudis Gómez de Avellaneda «andaba un gallego repartiendo puñetazos entre los espectadores que protestaban», (Ferrero y Ventura, 1997: II8) sin duda, la alusión del periódico satírico no podía ser más directa al poeta zamorano.

Tal era la obstinación con la que Juan Nicasio Gallego asesoraba literariamente a Gertrudis Gómez de Avellaneda, que algunas malas lenguas comentarían con malicia que le ayudaba a escribir las obras de teatro. Por ello, cuando ya había fallecido Juan Nicasio Gallego, la publicación Cabezas y cabezadas trazaría en verso unas semblanzas satíricas queriendo resaltar, a su manera, el mérito de Avellaneda:

$$
\begin{gathered}
\text { De Juan Nicasio Gallego } \\
\text { alumna dicen que fue } \\
\text { ni lo afirmo ni lo niego, } \\
\text { pero ella es que ha escrito luego } \\
\text { como Dios sabe y yo sé. } \\
\text { (Del Palacio y Rivera, 1864: 6or). }
\end{gathered}
$$

Pero más allá del caso concreto de Gómez de Avellaneda, sería tal el recuerdo y el cariño que los jóvenes autores de su época sintieron por la persona de Juan Nicasio

5 Enciclopedia pintoresca universal. Periódico satírico mensual que se publicó en Madrid entre los años I844 y I846. 
Gallego, que incluso décadas después de su desaparición se siguieron publicando homenajes hacía el zamorano en diferentes periódicos del país. Como en este caso del año I880 - justo en la frontera de nuestro marco cronológico, pero que posiblemente fuera redactado en el año anterior- donde Narciso Campillo publicará en el interior del periódico literario semanal ilustrado Día de Moda, un soneto dedicado al zamorano, y cuyo título rezaba A la memoria de D. Juan Nicasio Gallego, y dice lo siguiente:

Cuando cantó, su voz de gena sonido

Absortos los poetas escucharon;

Que en esa voz unísonos vibraron

Ecos de gloria y funeral gemido.

Cuando murió, su espíritu encendido

Voló al cielo, su cuerpo sepultaron;

Más sus divinos versos nos quedaron

Vencedores del tiempo y del olvido.

En ellos para siempre resplandece

El tesoro del habla castellana,

Que amenaza rugiendo o flébil llora.

Y por ellos con hondo amor le ofrece,

Mientras su tumba en lauros engalana,

Admiración y gratitud Zamora.

(Día de Moda, nº 20, 2I-6-I880: Io).

\section{La imagen de Juan Nicasio Gallego en la prensa}

Más allá de la imagen mostrada por el Juan Nicasio Gallego poeta, y la que emanan de los homenajes realizados por sus amigos y seguidores, existe una serie de publicaciones, noticias y notas en las que se nos muestra otra faceta del zamorano. Algunas de ellas son publicaciones oficiales, la mayor parte de ellas publicadas en la Gaceta de Madrid, y otras más curiosas, aparecidas en publicaciones más desconocidas o de menor calado social, pero donde podemos apreciar la imagen emanada por Juan Nicasio Gallego en los últimos años de su existencia.

Será de ese modo como el 28 de septiembre de 1833 , y tras ya haber conseguido el zamorano el total perdón real de Fernando VII, se le concedería el puesto de Conjuez del Excusado, ocupando la plaza vacante que había dejado Bernardo del Río tras su fallecimiento. Del mismo modo, y así lo recogería su buen amigo Pastor Díaz en su Galería de españoles célebres contemporáneos de 1845, «algún tiempo después por el ascenso de Francisco Ranero a la Colectora General de Espolios, ocuparía Gallego una plaza supernumeraria en la Rota de la Nunciatura, de cuyo tribunal ya era auditor desde 1820». (Pastor Díaz, 1845: 47).

Sin embargo, su alegría por los nuevos puestos le duraría poco, pues años después, en octubre de 1849, el Eco del Comercio publicaría un anuncio firmado por el vocal secretario de la Junta provisional del gobierno en la que se notifica de manera pública la suspensión de los puestos que ocupaba el zamorano:

La junta provisional del gobierno de esta provincia ha tenido a bien suspender provisionalmente de sus respectivos destinos a los sujetos siguientes: Sr. D. Juan Nicasio Gallego de auditor supernumerario de la Rota, y conjuez del Tribunal del

Excusado. (Eco del Comercio, 9-Io-I849: I). 
No duraría mucho esta suspensión, al menos la del Tribunal del Excusado, si atendemos a lo que publicaría en el año I84I la Gaceta de Madrid, donde se puede leer el anuncio en que se aclara que ya se ha resuelto el asunto de la suspensión provisional de Juan Nicasio Gallego en el puesto de conjuez del Tribunal del Excusado:

El Regente del Reino en consideración a los distinguidos méritos literarios y padecimientos por la causa de la libertad de D. Juan Nicasio Gallego, Diputado que fue de las Cortes Generales y Extraordinarias de Cádiz; ha tenido a bien resolver que vuelca al ejercicio de la plaza de conjuez decano del tribunal apostólico y Real de la gracia del Excusado de que fue suspendido por la junta provisional de gobierno de Madrid. (Gaceta de Madrid, 7-6-1841: I).

«Sería también nombrado, tres años después, Consiliario de la Real Academia de Nobles Artes de San Fernando» (Gaceta de Madrid, I-6-I844: I), sin embargo, y a pesar de la gran cantidad de puestos desempeñados por el zamorano en la Corte, éste no olvidará sus orígenes, y al igual que en etapas anteriores de su vida lo demostraría volviendo cuando le era posible a visitar su tierra de origen, e incluso escribiendo diferentes composiciones poéticas dedicadas a Zamora, tales como $A$ mi vuelta a Zamora, o el titulado $\mathrm{Al}$ Ilustrísimo obispo de Zamora en sus días. De este modo, el ya reconocido personaje volvería a visitar su ciudad de nacimiento en algunas ocasiones, viajando para ello desde la Corte.

La Gaceta de Madrid recogería en sus páginas uno de estos viajes realizados, por el sacerdote y poeta, a la ciudad del Duero; concretamente la que realizó en junio del año I844:

Hoy a las 9 de la mañana ha tenido la satisfacción Zamora de recibir en su seno al respetable D. Juan Nicasio Gallego, que después de diez años no había visitado el país que le vio nacer. Parece que permanecerá solo unos ocho días, regresando luego a esa corte, donde le llaman deberes interesantes al servicio público. La innumerable concurrencia que le felicita por su llegada, paga de este modo el tributo que debe á sus eminentes cualidades, manifestándole la estimación, que nunca será bastante cual merece tan gran talento. (Gaceta de Madrid, 26-5-1844: I).

Seguiría el zamorano recibiendo premios y nombramientos a lo largo de sus últimos años; desde Senador vitalicio del Reino, hasta Secretario Perpetuo de la Real Academia Española, donde le seguían recordando años después de su fallecimiento, como ocurrió en el año 1876, cuando Antonio Arnao elogió su figura en el discurso que leyó ante dicha institución cuando se inauguró la sesión pública de aquel año.

De uno de estos varones que en la poética república de las letras inmortalizaron su nombre, haciéndolo cruzar victorioso por donde quiera que resuene la rotunda lengua de Cervantes, y conquistando para él laurel imperecedero con las manifestaciones poéticas de su numen. [...] Juan Nicasio Gallego se halla retratado el autor como individuo. Sentimientos nobles, afectos apasionados, aspiraciones elevadas, amor a la Patria, cultura en los gustos, respeto a la virtud; todas esas cualidades, y otras muchas más, resplandecen en ellos como claros reflejos de su pura naturaleza moral. [...] Donde la autoridad reclamada veneración, él se la tributaba; donde el bien debía fructificar, él nunca negaba la semilla de su consejo; donde arrancaba lágrimas de dolor, él estaba presente con sus consuelos; y si no pudo amar a la mujer 
en la pasión que se santifica ante el altar, ni defender la Patria con las armas en las manos, profesó en ocasiones a la primera más pura y acentuada amistas, a la par que servía a la segunda con la abnegación de su pecho y con las luces de su espíritu.

[...] Latinista profundo, hasta poder hallarse tan familiarizado con el idioma de Horacio como lo estaba con el de Cervantes; humanista consumado, de modo que un crítico en las diversas materias que abarca esta parte de la instrucción era solicitado, oído y respetado como criterio de maestro; sabio eclesiástico, cuanto se requiere para llevar con honra el título académico, que le ennoblecía, de doctor en ambos derechos; literario erudito, en grado que le consentía conocer a fondo autores de maestros del Siglo de Oro, y por último, poeta elegante, vigoroso y correcto. [...] Señores académicos, nuestro compañero fue bueno como hombre, y excelente como poeta. Dedicadle por tanto un tierno recuero en el corazón, y levantadle con generoso aplauso un momento para la posteridad, la amistad lo pide, la Patria lo reclama, las letras lo necesitan. (Biblioteca de la Real Academia Española, M-RAE, AC. Esp. I-94; 3-3I).

Sin embargo, y a pesar de su alegría por el nuevo reconocimiento, Juan Nicasio Gallego no fue capaz de tomar posesión del que sería su último puesto eclesiástico concedido: el de la dignidad de arcipreste de la Iglesia del Pilar de Zaragoza en el año I85. Es muy probable que la imposibilidad de tomar posesión de este último puesto eclesiástico, se debiera a una enfermedad que sufrió Nicasio Gallego a lo largo del año de I851. Una enfermedad que debió ser realmente grave para el zamorano, pues apareció incluso en la prensa. Concretamente en una publicación satírica de ciencias médicas, La linterna médica, en la que utilizaron la enfermedad del zamorano para cargar sus burlas contra la homeopatía:

El Sr. D. Juan Nicasio Gallego, persona tan conocida por su importancia literaria, como por la política y religiosa, cayó enfermo poco hace, de tanta gravedad que todo el mundo llegó a temer por su vida. No faltó quien, seducido por la charla de la homeopatía, le aconsejase se entregara en manos de los globuleros. Pero el señor Gallego que a su buen juicio y vasta erudición une un carácter inflexible, no tuvo por conveniente acceder a tal insinuación, y gracias á esto y á la verdadera medicina, representada por uno de los profesores más conocidos de la capital, el Sr. D. Juan Nicasio Gallego está hoy totalmente restablecido, y en el seno de sus apasionados y amigos. Si la homeopatía entra por las puertas de su casa, a estas horas ya habríamos sentido su muerte». (La Linterna Médica, 24-2-1851: 15).

A pesar de que la salud del sacerdote y poeta zamorano no estaba pasando por su mejor momento desde hacía ya bastante tiempo, su fallecimiento se produciría, como veremos a continuación, en los primeros días del mes de enero del año de 1853, y no en marzo del año I846 como algunos medios de prensa llegaron a hacer público en sus páginas. Otro dato curioso más que envuelve los últimos años de la vida de Juan Nicasio Gallego, y que la Gaceta de Madrid se vio obligada a publicar para desmentir con el siguiente texto:

En un periódico de esta corte se dijo ayer que había fallecido el Sr. D. Juan Nicasio Gallego. Pocos ignorarán ya en Madrid que por fortuna no es cierta semejante noticia, ni ha tenido fundamento alguno; más para evitar el sentimiento que en las provincias pudiera causar a los deudos y amigos del supuesto difunto, nos apresuramos a desmentirla». (Gaceta de Madrid, I2-3-1946: 2). 
Debería finalmente, Juan Nicasio Gallego su fallecimiento a una mala caída, que sufriría la noche del día 22 de diciembre del año i85I mientras se hallaba paseando por la plaza de Oriente; así lo contará su amigo Eugenio Ochoa en la introducción del libro de poemas que la Real Academia le dedicará al zamorano en i854. En aquel momento se dedicaba a la contemplación de la lucida iluminación que mostraba el Palacio Real, y con la que se había decidido solemnizar el nacimiento de la señora Princesa de Asturias. El golpe, que recibió tras caer de espaldas a pesar de procurar en vano sostenerse asido a un árbol, fue tan violento que le originaría la rotura, o más bien la luxación, de la cabeza del hueso del muslo izquierdo. «Esta lesión grave siempre, y que lo era mucho más atendiendo a la avanzada edad del paciente, se fue complicando además con la fuerte afección asmática que ya le agobiaba de antiguo». (Gallego, 1854: I2-13).

Será del siguiente modo como, una vez fallecido el zamorano en su habitación del viejo edificio de la Real Academia Española, en la calle Valverde de Madrid, lo recogerá la Gaceta de Madrid el día in de enero de 1853:

El Excmo. Sr. D. Juan Nicasio Gallego, Senador del reino, gran cruz de la Real orden de Isabel la Católica,Juez Auditor de número de la Rota la Nunciatura apostólica, individuo del Real Consejo de Instrucción pública, dignidad de arcipreste del Pilar en el arzobispado de Zaragoza, Presidente de la Real Academia de Nobles Artes de San Fernando y Secretario perpetuo de la española ha fallecido ayer, y su cadáver será conducido á las dos de la tarde del día de hoy de la iglesia parroquial de San Ildefonso al cementerio de la sacramental de San Justo y San Miguel.

Aunque este doloroso suceso estuviese previsto ha mucho tiempo, por el mal estado de la salud del ilustre anciano desde que sufrió en febrero anterior la caída que indudablemente aceleró su muerte, no dejará de causar profundo sentimiento a cuantos conocían al Sr. Don Juan Gallego, y a todos los amantes de las letras.

Con aquel poeta y escritor distinguido desaparece casi el último representante de una generación de hombres eminentes por su saber que honraban a principios del siglo la literatura española. El castizo Reinoso, el maestro de la juventud estudiosa Lista, el culto Hermosilla, el erudito Miñano, el Duque de Frías, dos veces ilustre, todos, todos han bajado a la tumba, aunque legándonos obras insignes y perdurables ejemplos. Solo nos queda como resto de aquella época el venerable Quintana, cuya vida prolongue el cielo.

E1 Sr. D. Juan Nicasio Gallego ha muerto casi octogenario, colmado de honores y distinciones, objeto de veneración y de cariño para sus amigos y discípulos. Menos fecundo que correcto, pero dotado de purísimo gusto, cuanto ha salido de su pluma se distingue por su elevación, por su estilo, por su pureza. Autoridad en nuestra lengua, ha cooperado activamente a todos los utilísimos e importantes trabajos de la Academia española. La última edición del Diccionario de esta corporación es quizás lo último también en que él ha puesto la mano. Las altas cualidades de su carácter, su ciencia, su recto juicio, además de su edad, le habían hecho el patriarca de nuestra literatura, y el Mentor de los literatos. Cuando alguno de nuestros primeros escritores, Breton como Vega, Hartzenbusch como el Duque de Rivas, Zorrilla como Rubí, habían terminado una historia, un drama, una poesía, antes de someterla al juicio inapelable del público, iban a someterla al fallo ilustrado, aunque severo, de D. Juan Nicasio Gallego. Sus correcciones eran aceptadas por todo sin repugnancia y con gratitud; sus elogios, como la consagración del mérito. Otras veces, con la fruición que tiene el verdadero talento en proteger al talento, el Sr. 
Gallego, tendía la mano a un joven, poco antes oscuro y desvalido, y le investía con el noble título de poeta.

No escribimos ahora una necrológica: eso tendrá efecto otro día. Nuestro único objeto ha sido derramar los primeros una lágrima y una flor sobre el féretro que encierra los restos de un varón preclaro, como más tarde y hoy mismo las derramaremos sobre el sepulcro. (Gaceta de Madrid, IO-I-I853: 4).

Según la misma publicación de la Gaceta de Madrid del día 24 de enero de 1853, el día I8 de ese mismo mes, la publicación «La Paz de Sevilla había informado que la catedral de aquella ciudad había celebrado unas honras por el alma de Juan Nicasio Gallego, quién había ocupado la canonjía de aquel templo tiempo atrás». (Gaceta de Madrid, 24-I-I853: 3). Para el día después del sepelio del poeta y político zamorano, publicar en sus páginas la siguiente crónica de la noticia:

Ayer a las dos de la tarde fue conducido a la última morada el cadáver del Sr. D. Juan Nicasio Gallego. En el acompañamiento fúnebre figuraban muchos altos personajes, y casi todos nuestros literatos y periodistas.

Al depositar el féretro en la huesa el Sr. Martínez de la Rosa pronunció algunas elocuentes palabras, que conmovieron hasta hacer derramar lágrimas á cuantos las escucharon. Era muy cerca del anochecer cuando regresaron a Madrid los que habían acudido a rendir aquel postrer homenaje de estimación y respeto al ilustre decano de la literatura española. (Gaceta de Madrid, II-I-I853: 2).

La tumba de Juan Nicasio Gallego sería coronada con una placa donde podía leerse un epitafio en homenaje al finado. Sin embargo y debido a la remodelación que se hizo en el patio donde estaba inhumado el insigne poeta zamorano, sus restos fueron trasladados al nicho situado en la fila $4^{\circ}$, número 27 del mismo patio de San Miguel, junto a la entrada principal de la capilla. Será en su interior, junto a los restos del zamorano, donde se encuentra la vieja lápida, escondiendo de la vista del curioso y viejo epitafio que decía lo siguiente:

\author{
HOMBRE DE BIEN Y \\ PATRIOTA ESCLARECIDO, \\ AFABLE, DISCRETO. \\ PIADOSO, MODELO DE AMIGOS, \\ LUSTRE Y AMAPARO DE SU FAMILIA, \\ ORÁCULO DEL BUEN GUSTO EN \\ LETRAS Y ARTES. \\ (Pino Gutiérrez, I995: 34).
}

\title{
5. El último homenaje
}

Para finalizar este amplío y minucioso recorrido por el imaginario nacional de Juan Nicasio Gallego, debemos hacer una última parada en el año ı879; dos años después de que se cumpliera el primer centenario del nacimiento del zamorano. Será entonces cuando su ciudad natal decidiera planearle un reconocimiento en forma de homenaje. El promotor de todos estos actos será Luis Rodríguez Miguel, ${ }^{6}$ catedrático numerario de

6 Luis Rodríguez Miguel (I844-I916), archivero, bibliotecario y anticuario, fue licenciado en filosofía y letras por 
retórica y poética del Instituto de Zamora, quien expresaría en sendas cartas enviadas a los directores de los periódicos con mayor tirada de la época en la ciudad y la provincia de Zamora, El Eco del Duero y La Enseña Bermeja, lo necesario de la conmemoración del que fuera uno de sus hijos más ilustres. En esas cartas se podía leer lo siguiente:

Señor director. Zamora, 9 de octubre de 1879 .

Muy señor mío: Constituye el más preciado blasón de los ciudadanos de todos los tiempos, haber sido cuna de esos afortunados seres que hizo brillar el genio ocupando un lugar eminente entre los hombres de su época. Zamora cuenta entre los muchos hombres ilustres de ciencia, virtud y armas, uno que, quizá por privilegio singular, reunió tan evidenciables títulos, y que por pertenecer a nuestro tiempo no es menos digno de que se haga de él especial memoria. Efectivamente, don Juan Nicasio Gallego, virtuoso sacerdote eminente patricio y excelente poeta, merece que su natalicio se conmemore de una manera digna por la ciudad que le vio nacer.

Ignoro si antes de ahora se ha iniciado este pensamiento, y aún si llegó a realizarse alguna vez; pero de todos modos, no creo ofender a nadie, ni nadie debe darse por ofendido porque un amante de las glorias literarias trate de rendir justo tributo de admiración a un hijo ilustre de la ciudad donde hoy reside. Por otra parte, no se me alcanza los obstáculos que pudieran oponerse al pensamiento de solemnizar el día I4 de diciembre en que hará ciento dos años que vio la luz en Zamora don Juan Nicasio Gallego contando con el apoyo de Vd. y de sus ilustres redactores de la Enseña Bermeja, ${ }^{7}$ corresponde llevar a feliz término lo que me atrevo a indicarle.

Para terminar, debo manifestar que a mi juicio una suscripción con el carácter popular abierta en los respectivos periódicos para allegar recursos que puedan invertirse en colocar una modesta lápida conmemorativa en la casa donde nació, y una sesión artística literaria en el Teatro, son los bastante para que Zamora demuestre que no es ingrata con sus hijos.

Cuente Vd. con mi óbolo y débil apoyo para tal objeto, así como el testimonio de reconocimiento de s.s.q.b.s.m.

Luis Rodríguez Miguel. (Ferrero y Ventura, I997: II9).

De forma inmediata, espoleados por la misiva, los dos periódicos zamoranos comenzaron a preparar el homenaje para conmemorar el nacimiento de Juan Nicasio Gallego. Lo primero que hicieron fue dirigirse a las entidades públicas para solicitarles su participación, y de paso para que nombrasen un representante que pasaría a formar parte de la Comisión que debería crearse en la ciudad para tal efecto. Esta Comisión organizadora estaría finalmente compuesta por: «Felipe Rodríguez, representando la Diputación, José Alonso Manjón, por el ayuntamiento de la ciudad; y Ursicio Álvarez, Anacleto G. Abadía, Luis Rodríguez Miguel y Antonio L. Núñez Villabrille, por parte de la prensa zamorana». (Ferrero y Ventura, 1997: 120).

Será de ese modo como se llegaría al día elegido para al día elegido para llevar a cabo la celebración del homenaje; el I4 de diciembre de i879. Esa mañana caía sobre la capital zamorana una copiosa nevada que a punto estuvo de evitar que se llevara a cabo los diferentes actos programados. A pesar de todo, la ciudad bullía de gente. El periódico La Enseña Bermeja dedicó el número de ese día a ofrecer una biografía del homenajeado,

la Universidad de Madrid. En I886, y tras hacer un periplo que le llevaría a ocupar diferentes puestos en las ciudades de Toledo, Zamora y Guadalajara, sería nombrado catedrático de literatura en la Universidad de Salamanca, donde ocuparía su cátedra hasta su fallecimiento.

7 El mismo texto sería enviado a la redacción del Eco del Duero. 
donde aparecía un grabado con la imagen de su casa natal realizado por José Gutiérrez «Filuco»: otro buen ejemplo de imaginario nacional, mediante la imagen, pero que por desgracia no se ha conservado.

A las doce menos cuarto de la mañana se juntaron en el ayuntamiento de Zamora las autoridades civiles y eclesiásticas: salvo la del obispo que excusó su asistencia por tener función en la iglesia de San Vicente. Se tocó el reloj y la Queda, siguiendo la tradición zamorana que dice: Fiesta zamorana, reloj y campana. Saldría después de las Casas Consistoriales la comitiva, precedida por clarín y maceros; tras ellos, aparecieron la Comisión gestora del homenaje y el alcalde de la ciudad don Pedro Cabello Septién. Al paso del cortejo, las bandas de música de la ciudad y la del Hospicio, comenzaron a tocar mientras en los balcones lucían valiosas colgaduras. Por su parte la familia del artista, para conmemorar el evento, enviaría a los alcaldes de barrio quinientos bonos de socorro para que fueran repartidos entre los pobres de solemnidad.

La casa donde nació Juan Nicasio Gallego estaba situada en la llamada calle de las Lonjas, que iba desde la calle de la Reina hasta la Plaza Mayor de la capital, muy cerca de las Casas Consistoriales de donde partió la comitiva. Por ello, pronto dicha comitiva se detuvo ante el edifico en que nació el homenajeado, para que acto seguido el alcalde y la Comisión subieran al balcón del primer piso desde donde se descorrió la cortina que cubría la placa que la ciudad había decidido dedicar al escritor.

Grabada en ella aparecía el siguiente texto:

\author{
ZAMORA Y SU PROVINCIA \\ AL EXIMIO POETA \\ DON JUAN NICASIO GALLEGO \\ NACIDO EN ESTA CASA EL I4 DE DICIEMBRE DE ${ }_{7777}$ \\ DEDICAN EN IGUAL DIA DE 1879. \\ (Ferrero y Ventura, 1997: 120).
}

Sobre la recién estrenada placa se había colocado una corona de bronce cincelada, ofrenda de la Real Academia Española, de la que Juan Nicasio Gallego, como hemos comentado con anterioridad, fue miembro y Secretario Perpetuo. Por la noche de ese día, con la nieve cubriendo calles y plazas, se celebraría una velada literaria en el Teatro Principal de Zamora, cedido para ese fin por el propietario señor Calamiro; «Cesáreo Fernández Duro sería el elegido para llevar a cabo la presentación del acto, y tras un leve discurso descorrió la cortina que cubría un retrato de Juan Nicasio Gallego que se encontraba situado en el centro del escenario». (Ferrero y Ventura, 1997, I20).

\title{
6. Conclusiones
}

Podemos suponer, leyendo lo anterior, que la figura de Juan Nicasio Gallego ha debido de pasar a la historia como un personaje destacado de la sociedad española en general, y del zamorano en particular. Sin embargo, nada más lejos de la realidad.

Si empezamos por recordar que el homenaje por su centenario, dado por sus paisanos, se llevó a cabo con dos años de retraso, y por la insistencia de una persona ajena a las instituciones, ya tenemos una pista clara del futuro que esperaba a la memoria del poeta, sacerdote y político zamorano. A esto, habría que sumar que tanto la placa, como la corona cincelada, colocada en su casa de la capital zamorana, desaparecieron sin dejar rastro en el año I893, tan solo trece años después de su colocación, debido a una restructuración de la plaza Mayor de Zamora en que se derruyó el edificio donde había 
nacido Juan Nicasio. Tampoco se conserva la placa de su tumba, donde se mostraba el tan elegante epitafio dedicado por sus compañeros de letras, pues el cementerio de San Justo quedó destrozado tras los enfrentamientos llevados a cabo en las inmediaciones durante la Guerra Civil Española. Tras la reconstrucción del campo santo, las tumbas del Cuartel de San Miguel, donde se encontraban los restos de Juan Nicasio Gallego, fueron recolocadas en las paredes laterales en forma de nicho. En ese espacio, donde se recolocarían los restos del zamorano, se introduciría también, borrándola de la vista de todo el mundo, esa placa de mármol con las últimas palabras, en forma de bello epitafio, dedicadas al poeta zamorano.

A pesar de los numerosos reconocimientos recibidos en la última etapa de su vida, serán mínimas las crónicas que hasta nuestros días han llegado, en el caso de que existiera alguna más, del poeta y político zamorano. A pesar de ello, por la información que conocernos de él, ya sea en o publicado en libros recopilatorios de los autores contemporáneos, ya sea en artículos de prensa o por mediación de los archivos, podemos hacernos una visión, más o menos completa, de lo que fue la vida y obra de uno de los zamoranos más sobresalientes de la historia. Tan brillante como poco reconocido.

\section{BibLIOgRAFÍA}

De Cueto López de Ortega, Leopoldo Augusto, (1871) Biblioteca de autores españoles, desde la formación del lenguaje hasta nuestros dias. (7I tomos), Madrid, Imprenta de Manuel Rivadeneyra.

Del Palacio, Manuel y Rivera, Luís, (I864) Cabezas y cabezadas, Madrid, Librería de D. Miguel Guijarro.

Ferrer del Río, Antonio, (r846) Galería de la literatura española, Madrid, Establecimiento tipográfico de D.F. de Mellado.

Ferrero Ferrero, Florián y Ventura Crespo, Concha, (1997) Zamoranos Ilustres, Zamora, Editorial Prensa Ibérica.

Freire López, Ana María, (2000) «El anti-romanticismo de Juan Nicasio Gallego» en Actas del VII Congreso de la poesia romántica, número 7, Centro Internacional de Estudios sobre Romanticismo Hispánico-Instituto italiano per gli studi filosofici, 2000, pp. 8I-88.

- (2003) «Un zamorano en las Cortes de Cádiz» en Anuario del Instituto de Estudios Zamoranos Florián de Ocampo, número 20, Instituto de Estudios Zamoranos Florián de Ocampo, 2003, pp. 291-30I.

Gallego Hernández, Juan Nicasio, (1854) Obras poéticas de Juan Nicasio Gallego, secretario perpetuo de la Real Academia Española publicadas por la misma academia, Madrid, Imprenta del Diccionario Universal del Derecho Español Constituido.

Mor De Fuentes, José, (1836) Bosquejillo de la vida y escritos delineado por él mismo, Barcelona, Imprenta de D. Antonio Bergnes.

Pastor Díaz, Nicomedes, (1845) Galería de españoles célebres contemporáneos o biografias y retratos, t. viII, Madrid, Imprenta y librería de D. Ignacio Boix.

Pérez Galdós, Benito, (2008) Los Apostólicos, Barcelona, Editorial Espasa Calpe.

Pino Gutiérrez, Juan Antonio, (1995) Sacramental de San Junto, Madrid, Editorial Paracelso.

\section{Archivos}

Archivo Histórico de la Universidad de Salamanca. Registro de exámenes de estudiantes para el ingreso en la Facultad Mayor. Volumen No\%, años I769-18ı7, p. 246.

Biblioteca de la Real Academia Española. M-RAE, AC. Esp. I-94, pp. 3-3I. 


\section{Periódicos y revistas}

Día de Moda, Madrid, número 20, 2I de junio de 1880.

El Artista, Madrid, número I, 5 de enero de 1835 .

Eco del Comercio, Madrid, 9 de octubre de 849, p. I,

Gaceta de Madrid, Madrid, lunes 7 de junio de I84I, p. I.

La Linterna Médica, Madrid, 24 de febrero de 1846, p. 2.

Museo de las familias, Madrid, número I, 25 de enero de 1842. 